\title{
GABA levels and measures of intracortical and interhemispheric excitability in healthy young and older adults
}

Citation for published version (APA):

Hermans, L., Levin, O., Maes, C., van Ruitenbeek, P., Heise, K-F., Edden, R. A. E., Puts, N. A. J., Peeters, R., King, B. R., Meesen, R. L. J., Leunissen, I., Swinnen, S. P., \& Cuypers, K. (2018). GABA levels and measures of intracortical and interhemispheric excitability in healthy young and older adults: an MRS-TMS study. Neurobiology of Aging, 65, 168-177.

https://doi.org/10.1016/j.neurobiolaging.2018.01.023

Document status and date:

Published: 01/05/2018

DOI:

10.1016/j.neurobiolaging.2018.01.023

Document Version:

Publisher's PDF, also known as Version of record

\section{Document license:}

Taverne

Please check the document version of this publication:

- A submitted manuscript is the version of the article upon submission and before peer-review. There can be important differences between the submitted version and the official published version of record.

People interested in the research are advised to contact the author for the final version of the publication, or visit the DOI to the publisher's website.

- The final author version and the galley proof are versions of the publication after peer review.

- The final published version features the final layout of the paper including the volume, issue and page numbers.

Link to publication

\footnotetext{
General rights rights.

- You may freely distribute the URL identifying the publication in the public portal. please follow below link for the End User Agreement:

www.umlib.nl/taverne-license

Take down policy

If you believe that this document breaches copyright please contact us at:

repository@maastrichtuniversity.nl

providing details and we will investigate your claim.
}

Copyright and moral rights for the publications made accessible in the public portal are retained by the authors and/or other copyright owners and it is a condition of accessing publications that users recognise and abide by the legal requirements associated with these

- Users may download and print one copy of any publication from the public portal for the purpose of private study or research.

- You may not further distribute the material or use it for any profit-making activity or commercial gain

If the publication is distributed under the terms of Article $25 \mathrm{fa}$ of the Dutch Copyright Act, indicated by the "Taverne" license above, 


\title{
GABA levels and measures of intracortical and interhemispheric excitability in healthy young and older adults: an MRS-TMS study
}

\author{
Lize Hermans ${ }^{a}$, Oron Levin ${ }^{a}$, Celine Maes ${ }^{a}$, Peter van Ruitenbeek ${ }^{a, b}$, \\ Kirstin-Friederike Heise ${ }^{a}$, Richard A.E. Edden ${ }^{c, d}$, Nicolaas A.J. Puts ${ }^{c, d}$, Ronald Peeters ${ }^{\text {e, }}$ \\ Bradley R. King ${ }^{\mathrm{a}}$, Raf L.J. Meesen ${ }^{\mathrm{a}, \mathrm{f}}$, Inge Leunissen ${ }^{\mathrm{a}}$, Stephan P. Swinnen ${ }^{\mathrm{a}, \mathrm{g}}$, \\ Koen Cuypers ${ }^{\mathrm{a}, \mathrm{f}, *}$
}

\footnotetext{
a Movement Control and Neuroplasticity Research Group, Department of Movement Sciences, Group Biomedical Sciences, KU Leuven, Leuven, Belgium

${ }^{\mathrm{b}}$ Department of Neuropsychology and Psychopharmacology, Maastricht University, Maastricht, MD, the Netherlands

${ }^{c}$ F.M. Kirby Research Center for Functional Brain Imaging, Kennedy Krieger Institute, Baltimore, MD, USA

${ }^{\mathrm{d}}$ Russell H. Morgan Department of Radiology and Radiological Science, Johns Hopkins School of Medicine, Baltimore, MD, USA

e Department of Imaging \& Pathology, Biomedical Sciences Group, KU Leuven, Leuven, Belgium

${ }^{\mathrm{f}}$ Rehabilitation Research Centre, Biomedical Research Institute, Faculty of Medicine and Life Sciences, Hasselt University, Diepenbeek, Belgium

${ }^{\mathrm{g}}$ Leuven Research Institute for Neuroscience \& Disease (LIND), KU Leuven, Leuven, Belgium
}

\section{A R T I C L E I N F O}

\section{Article history:}

Received 4 August 2017

Received in revised form 24 January 2018

Accepted 26 January 2018

Available online 6 February 2018

\section{Keywords:}

Aging

Gamma-aminobutyric acid (GABA)

Magnetic resonance spectroscopy (MRS)

Transcranial magnetic stimulation (TMS)

Intracortical inhibition

Interhemispheric inhibition

\begin{abstract}
A B S T R A C T
Edited magnetic resonance spectroscopy (MRS) and transcranial magnetic stimulation (TMS) have often been used to study the integrity of the GABAergic neurotransmission system in healthy aging. To investigate whether the measurement outcomes obtained with these 2 techniques are associated with each other in older human adults, gamma-aminobutyric acid (GABA) levels in the left sensorimotor cortex were assessed with edited MRS in 28 older (63-74 years) and 28 young adults (19-34 years). TMS at rest was then used to measure intracortical inhibition (short-interval intracortical inhibition/longinterval intracortical inhibition), intracortical facilitation, interhemispheric inhibition from left to right primary motor cortex (M1) and recruitment curves of left and right M1. Our observations showed that short-interval intracortical inhibition and long-interval intracortical inhibition in the left M1 were reduced in older adults, while GABA levels did not significantly differ between age groups. Furthermore, MRS-assessed GABA within left sensorimotor cortex was not correlated with TMS-assessed cortical excitability or inhibition. These observations suggest that healthy aging gives rise to altered inhibition at the postsynaptic receptor level, which does not seem to be associated with MRS-assessed GABA+ levels.

(C) 2018 Elsevier Inc. All rights reserved.
\end{abstract}

\section{Introduction}

Healthy aging is often accompanied by various motor declines, such as impaired coordination skills (Fujiyama et al., 2012) or deterioration of fine motor functions (Opie et al., 2015). Emerging evidence indicates that this could partly be explained by a reduced ability to regulate cerebral inhibition through activation of the gamma-aminobutyric acid (GABA) neurotransmitter system (Levin et al., 2014). Nevertheless, the effect of aging on GABAergic functioning remains poorly understood. So far, inconsistent findings have been reported due to small sample sizes and methodological variations (Bhandari et al., 2016). Furthermore, it is currently

\footnotetext{
* Corresponding author at: Movement Control and Neuroplasticity Research Group, Group Biomedical Sciences, KU Leuven, Tervuursevest 101, B-3001 Leuven, Belgium. Tel.: +32 (0) 16 376447; fax: +32 (0) 16329197.

E-mail address: koen.cuypers@kuleuven.be (K. Cuypers).
}

unclear whether (and how) the outcome measures of the different techniques that are used to assess GABA levels and properties of the GABA neurotransmitter system relate to each other in older adults.

Quantification of in vivo GABA levels in specific brain regions is possible using edited proton magnetic resonance spectroscopy (MRS) (Puts and Edden, 2012). With the use of MRS, acquiring information about regional variation of GABA levels in the brain across the human lifespan is now possible. Previous MRS studies have detected age-related reduction of GABA levels in prefrontal and parietal regions (Gao et al., 2013; Grachev and Apkarian, 2001; Grachev et al., 2001; Porges et al., 2017) and to a lesser extent in the sensorimotor cortex (SM1) (Grachev et al., 2001), suggesting that healthy aging is associated with regional changes in GABA levels. However, the study by Grachev et al. (2001) only included middleaged adults (40-52 years), thus data of older adults for the SM1 are lacking. It is of interest to note that variation in GABA levels within the sensorimotor cortices appears to not only be correlated with 
individual differences in motor performance, such as simple reaction time (Stagg et al., 2011a), but also predict neuroplasticity during motor skill acquisition (Kim et al., 2014; Stagg, 2014). Moreover, it has been observed that shifts in GABA levels, either an increase or decrease, were significantly related to motor ability in individuals with deficient neuromuscular control (Bhattacharyya et al., 2013). These observations suggest that changes in GABA levels within the primary motor cortex (M1) as a function of age may play a pivotal role in declines of motor functions.

While MRS allows in vivo quantification of GABA levels, transcranial magnetic stimulation (TMS) can be used to investigate GABAmediated physiological inhibition. Some TMS protocols can monitor activity of postsynaptic fast acting ionotropic $\left(G_{A B A}\right)$ and slower acting metabotropic $\left(\mathrm{GABA}_{\mathrm{B}}\right)$ receptors, which are activated by GABA, namely short-interval intracortical inhibition (SICI) and longinterval intracortical inhibition (LICI), respectively (Reis et al., 2008; Siebner et al., 1998; Ziemann et al., 1996). SICI involves a subthreshold conditioning stimulus (CS) that precedes a suprathreshold test stimulus (TS) by 2-4 ms (Kujirai et al., 1993; Ziemann et al., 1996), while LICI involves a suprathreshold CS that precedes a suprathreshold TS by 100-150 ms (Mcdonnell et al., 2006; Werhahn et al., 1999). The mechanisms of SICI at an interstimulus interval (ISI) of $1 \mathrm{~ms}$ are less known but might reflect extrasynaptic GABAergic activity (Stagg et al., 2011b). Other TMS protocols reflect the combination of GABA and glutamatergic activity including intracortical facilitation (ICF) and interhemispheric inhibition (IHI) between homologous M1s (Chen, 2004; Reis et al., 2008). More specifically, IHI allows the exploration of the activation of glutamatergic interneurons and local $G A B A_{B}$ receptors and their interactions (Chen, 2004; Reis et al., 2008). ICF can be measured with a subthreshold CS that precedes a suprathreshold TS by $8-30 \mathrm{~ms}$, whereas IHI can be explored with a suprathreshold conditioning and test stimulus and an ISI of $10-15 \mathrm{~ms}$ or $20-50 \mathrm{~ms}$. Finally, recruitment curves allow the investigation of the net effect of excitatory and inhibitory inputs. TMS is thus a powerful tool to investigate the neurophysiological mechanisms associated with age-related changes in the regulation of GABAergic inhibitory function.

So far, TMS studies investigating age-related changes in the GABAergic receptor system within M1 under resting conditions have obtained mixed results. Some studies reported that healthy aging is generally associated with a decline in inhibition (Heise et al., 2013; Peinemann et al., 2001), whereas other studies reported no impact of aging on inhibition (Stevens-Lapsley et al., 2013; Wassermann, 2002) or even increased inhibition in older adults (Kossev et al., 2002; McGinley et al., 2010). These studies addressed either the whole lifespan (Heise et al., 2013; Wassermann, 2002) or compared young to middle-aged (Kossev et al., 2002; Peinemann et al., 2001) or older adults (McGinley et al., 2010; Stevens-Lapsley et al., 2013), which compromises comparison of their results. Discrepancies in methodological factors such as application of different TMS protocols or the use of different TMS equipment add to this difficulty. A recent meta-analysis showed a slight but no significant decline in SICI in older as compared to young adults (Bhandari et al., 2016). However, it should be noted that some studies showing a significant decrease in SICI were not included in this report (i.e., Heise et al., 2013; Peinemann et al., 2001). While a few studies have already explored the effect of healthy aging on the excitability of both $G_{A B A}$ and $G A B A_{B}$ receptor systems in a single study design (Opie and Semmler, 2014, 2016; Smith et al., 2009), it is not yet clear how changes in MRS-determined GABA levels are associated with TMS measures of excitation and inhibition in older adults.

Here, we investigated the association between sensorimotor GABA levels and TMS measures of motor cortical excitability and inhibition in young and older adults. We expected that (1) sensorimotor GABA levels decrease with age and that (2) this decrease in GABA is related to changes in motor cortical excitability and inhibition, as assessed with TMS.

\section{Methods}

\subsection{Participants}

Twenty-eight healthy young adults (mean \pm standard deviation [SD]: $24.60 \pm 4.16$ years, age range: $19.92-34.50$ years, 14 women) and 28 healthy older adults (mean \pm SD: $69.07 \pm 3.09$ years, age range: $63.17-74.42$ years, 12 women) were recruited. We chose to include older adults between 63 and 75 years because lifespan studies have shown that this age range exhibits marked differences compared to young adults (20-35 years) in functional, structural, and neurochemical brain properties, such as lower GABA concentrations (Gao et al., 2013), gray matter atrophy (Serbruyns et al., 2015; Ziegler et al., 2012), and increases in functional connectivity (Solesio-Jofre et al., 2014). These effects are typically less pronounced in middleaged individuals (Serbruyns et al., 2015; Ziegler et al., 2012). Therefore, the use of extreme groups constitutes a more powerful design to study age-related changes. All participants were right-handed as determined via the Edinburgh Handedness Inventory (Laterality Index mean 91, range 33-100) (Oldfield, 1971), and none of them reported a history of neurological or psychiatric disorders, or using psychoactive medication. All older adults were screened for cognitive impairments using the Montreal Cognitive Assessment (Nasreddine et al., 2005) (mean \pm SD: $27.04 \pm 1.91$, range: 23-30). Sensorimotor functioning was assessed using the Purdue Pegboard Test in young (right hand mean \pm SD: $15.08 \pm 2.19$, left hand mean \pm SD: $14.61 \pm$ 1.50 , both hands mean \pm SD: $11.96 \pm 1.51$ ) and older adults (right hand mean \pm SD: $12 \pm 1.92$, left hand mean \pm SD: $11.39 \pm 1.39$, both hands mean \pm SD: $9.64 \pm 1.52$ ). None of the older adults had a score below the normative mean on all 3 task conditions (Desrosiers et al., 1995). The protocol was in accordance with the Declaration of Helsinki (1964), and the study was approved by the local medical ethics committee (University Hospital Leuven; MEC reference S58441). Exclusion criteria for TMS and magnetic resonance imaging were conformed to the current guidelines of the University Hospital Leuven, and informed consent was obtained from all participants.

\subsection{Procedure and data collection}

Participants first underwent the MRS session, followed by the TMS session on 2 separate days $\left(M_{\text {days }}=19\right)$, as discussed next.

\subsection{MRS session}

Scanning was completed on a Philips 3T Achieva dstream system (Philips Healthcare, the Netherlands) with a 32-channel receiver head coil. First, a high-resolution three-dimensional T1-weighted structural image (three-dimensional transient field echo (TFE), repetition time $=9.6 \mathrm{~ms}$, echo time $=4.6 \mathrm{~ms}$, inversion time $=900 \mathrm{~ms}, 0.98 \times$ $0.98 \times 1.2 \mathrm{~mm}^{3}$ voxels, field of view: $256 \times 256,160$ slices) was acquired. Then, MRS spectra were acquired in 2 voxel locations, that is, the left SM1 (region of interest) and occipital cortex (OCC; control region) positioned on the T1 image (Fig. 1). Data were acquired using the Mescher-Garwood point resolved spectroscopy (MEGA-PRESS) sequence (Mescher et al., 1996, 1998) (14 ms sinc-Gaussian editing pulses applied at an offset of $1.9 \mathrm{ppm}$ in the on experiment and $7.46 \mathrm{ppm}$ in the off experiment, repetition time $=2$ seconds, echo time $=68 \mathrm{~ms}, 40$ blocks of 8 -step phase cycles, $2-\mathrm{kHz}$ spectral width, excitation water suppression). Sixteen water-unsuppressed averages were acquired from the same voxel. The SM1 voxel $\left(3 \times 3 \times 3 \mathrm{~cm}^{3}\right)$ was centered over the left hand knob (Yousry et al., 1997), parallel to 

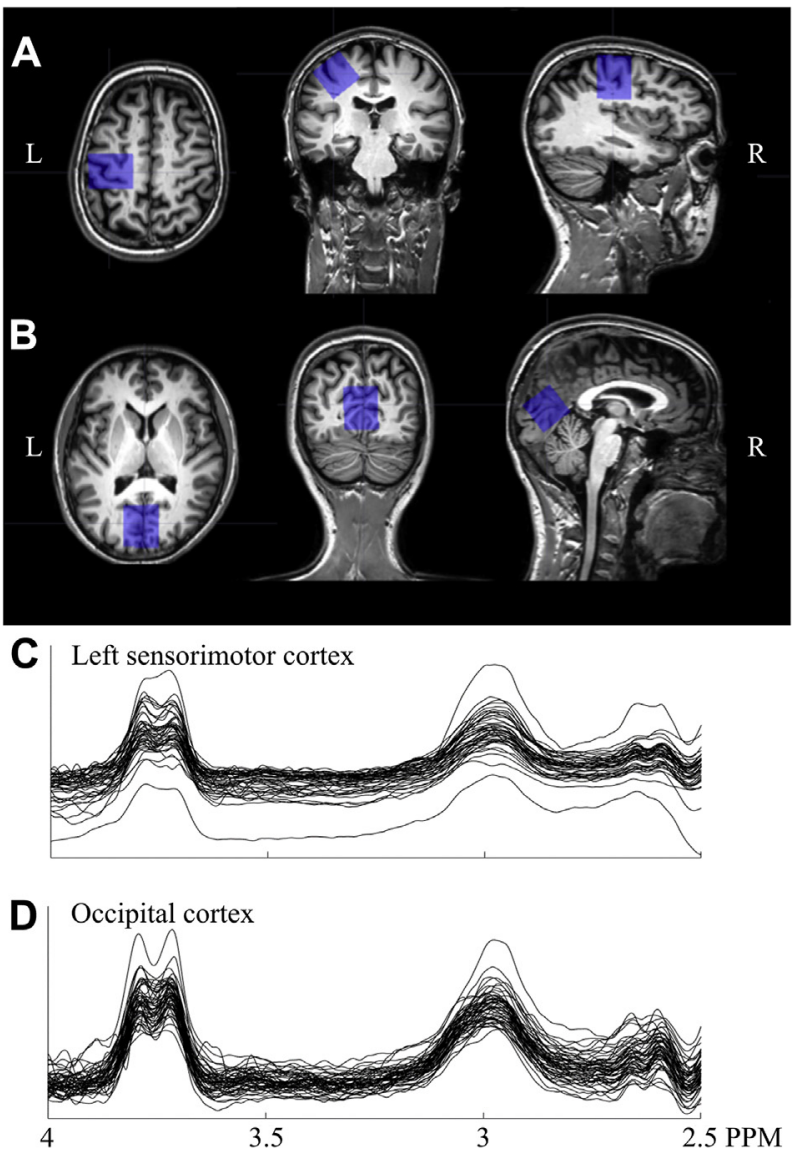

Fig. 1. Example of voxel placement for (A) the left sensorimotor cortex and (B) occipital cortex. Spectra from all participants included in the analysis for $(C)$ the left sensorimotor cortex and (D) the occipital cortex. The GABA+ peak is visible at $3 \mathrm{ppm}$. Abbreviations: GABA, gamma-aminobutyric acid; ppm, parts per million.

the anterior and posterior axes. One surface was parallel to the cortical surface in the coronal and axial views (Puts et al., 2011). The OCC voxel $\left(3 \times 3 \times 3 \mathrm{~cm}^{3}\right)$ was centered on the median line, aligned with the cerebellar tentorium in the sagittal plane, and positioned as posteriorly as possible (Puts et al., 2011).

\subsection{TMS session}

Age-related changes in corticomotor excitability, intracortical interactions within M1, and interhemispheric interactions (M1-M1) were evaluated with TMS using a BiStim ${ }^{2}$ configuration (Magstim, Whitland, Dyfed, UK). Coil configurations and stimulation parameters of the TMS paradigms are summarized in Table 1. Single-pulse TMS and paired-pulse TMS (ppTMS) paradigms were performed to investigate corticomotor excitability and intracortical interactions within M1. A dual-site TMS (dsTMS) paradigm was used to investigate IHI from the left M1 to the right M1. Coils were placed over the optimal position (hotspot) to elicit motor-evoked potentials (MEPs) in the right or left first dorsal interosseous (FDI) muscles and were oriented approximately $45^{\circ}$ lateral from the midline, with the handle pointing posteriorly to induce a posterior-anterior current. Electromyographic (EMG) signals were collected with disposable, self-adhesive $\mathrm{Ag} / \mathrm{AgCl}$ surface electrodes that were placed over the FDI muscles in both hands with a belly-tendon montage and were connected to a Bagnoli-16 EMG system (Delsys Inc., Boston, USA). The EMG signals were amplified (gain $=1000$ ), bandpass filtered $(20-2000 \mathrm{~Hz})$, and $50 / 60 \mathrm{~Hz}$ noise was eliminated (Humbug, Quest Scientific, North Vancouver, Canada). Subsequently these signals were digitized at $5000 \mathrm{~Hz}$ (CED Signal Version 4.03, Cambridge Electronic Design, Cambridge, UK) and stored for offline analysis.

For each participant, an orthogonal $1 \times 1 \mathrm{~cm}$ coordinate system was marked on a swimming cap with references to the left and right external auditory meatus, occiput, and vertex. The hotspots were defined as the M1 scalp locations from which 5 consecutive magnetic stimuli produced the highest mean MEP in relaxed left and right FDI muscles. Both hotspots were marked on the cap and captured using a magnetic resonance imaging-based neuronavigation system (Visor 2, ANT Neuro, the Netherlands and Brainsight, Rogue Research Inc, Montreal, Quebec, Canada) to monitor coil positions online during the experiment and to ensure optimal reproducibility of the stimulation location. The individual resting motor thresholds (rMT) were determined as the lowest stimulus intensity that produced MEPs greater than $50 \mu \mathrm{V}$ in the right and left FDI muscles in at least 5 of 10 consecutive trials when stimulating the hotspots. For each participant, TMS data acquisition was completed in the following order: (1) MEP recruitment curve for the left and right M1; (2) IHI from left M1 to right M1; (3) SICI and ICF; and (4) LICI from the M1 hand-knob area for right FDI stimulation. During the entire experiment, TMS measurements were performed while both FDI muscles were relaxed. Therefore, EMG was constantly monitored online, and the background EMG activity was kept below a threshold of $5 \mu \mathrm{V}$ peak-to-peak in the interval $50 \mathrm{~ms}$ before the first TMS pulse. To avoid TMS-related discomfort, no measurements were performed if the rMT of the left M1 exceeded $60 \%$ of the maximum stimulator output (Temesi et al., 2014). If the rMT of the right M1 exceeded $60 \%$ of the maximum stimulator output, the MEP recruitment curve for the right M1 and IHI was not performed. The TMS protocols are described in detail below (Section 2.4.1-2.4.4).

\subsubsection{MEP recruitment curve for the left and right $M 1 \mathrm{~s}$}

The recruitment curves of the left and right M1s were assessed using a single-pulse TMS paradigm. Stimulation intensities were set at $100 \%, 110 \%, 120 \%, 130 \%, 140 \%$, and $150 \%$ of rMT and were delivered in a pseudo-randomized order. MEPs from the left and right FDI were collected during 2 separate measurement blocks. Eight pulses per stimulus intensity were applied resulting in a total of 48 recorded MEPs per recruitment curve.

\subsubsection{Interhemispheric inhibition}

A dsTMS protocol was performed with each of the 2 Magstim $200^{2}$ units connected to a single coil. The coil used for the TS (outer diameter: $50 \mathrm{~mm}$ ) was positioned over the right M1 and was oriented approximately $45^{\circ}$ lateral from the midline. The coil used for the CS (outer diameter: $70 \mathrm{~mm}$ ) was positioned over the left M1 and was oriented approximately perpendicular to the midline. CS and TS intensities were set to $110 \% \mathrm{rMT}$ and $1 \mathrm{mV}$, respectively. Two ISIs were used: 10 and $40 \mathrm{~ms}$. It is assumed that short-latency IHI (ISI $\leq$ $10 \mathrm{~ms}$ ) is mediated by postsynaptic $\mathrm{GABA}_{\mathrm{A}}$ mechanisms (Chen, 2004), whereas postsynaptic $G_{A B} A_{B}$ receptors are involved at longer IHI latencies (ISI $\geq 40 \mathrm{~ms}$ ) (Irlbacher et al., 2007; Reis et al., 2008). Fifteen conditioned pulses (CS + TS) per ISI and 15 unconditioned pulses (TS alone) were given in a pseudo-randomized order, resulting in a total of 45 recorded MEPs.

\subsubsection{Short-interval intracortical inhibition and facilitation}

A ppTMS protocol was used to investigate SICI and ICF of the left M1. This TMS protocol was performed with a 1, 3, and $10 \mathrm{~ms}$ ISI (i.e., SICI $1 \mathrm{~ms}$, SICI $3 \mathrm{~ms}$, and ICF) with CS and TS intensities set at 80\% rMT and $1 \mathrm{mV}$, respectively. Fifteen conditioned pulses (CS + TS) for each ISI and 15 unconditioned pulses (TS alone) were delivered over 
Table 1

Summary of TMS protocols

\begin{tabular}{|c|c|c|c|c|c|c|c|}
\hline \multirow[t]{2}{*}{ TMS protocols } & \multicolumn{2}{|c|}{ Stimulation area } & \multicolumn{2}{|l|}{ Coil } & \multicolumn{2}{|c|}{ Stimulus intensity } & \multirow[t]{2}{*}{ ISI } \\
\hline & $\overline{\mathrm{CS}}$ & TS & $\overline{\mathrm{CS}}$ & TS & $\overline{\mathrm{CS}}$ & TS & \\
\hline \multicolumn{8}{|l|}{ spTMS } \\
\hline AURC left M1 & I & Left M1 & 1 & $70 \mathrm{~mm}$ & 1 & $\begin{array}{l}100 \%, 110 \%, 120 \%, 130 \% \\
140 \%, 150 \% \text { rMT }\end{array}$ & 1 \\
\hline AURC right M1 & I & Right M1 & 1 & $50 \mathrm{~mm}$ & 1 & $\begin{array}{l}100 \%, 110 \%, 120 \%, 130 \% \\
140 \%, 150 \% \text { rMT }\end{array}$ & I \\
\hline \multicolumn{8}{|l|}{ ppTMS } \\
\hline $\mathrm{SICI} / \mathrm{ICF}$ & Left M1 & Left M1 & $70 \mathrm{~mm}$ & $70 \mathrm{~mm}$ & $80 \%$ rMT & $1 \mathrm{mV}$ & $1 \mathrm{~ms}, 3 \mathrm{~ms}, 10 \mathrm{~ms}$ \\
\hline LICI & Left M1 & Left M1 & $70 \mathrm{~mm}$ & $70 \mathrm{~mm}$ & $1 \mathrm{mV}$ & $1 \mathrm{mV}$ & $100 \mathrm{~ms}$ \\
\hline \multicolumn{8}{|l|}{ dsTMS } \\
\hline $\mathrm{IHI}$ & Left M1 & Right M1 & $70 \mathrm{~mm}$ & $50 \mathrm{~mm}$ & $110 \%$ rMT & $1 \mathrm{mV}$ & $10 \mathrm{~ms}, 40 \mathrm{~ms}$ \\
\hline
\end{tabular}

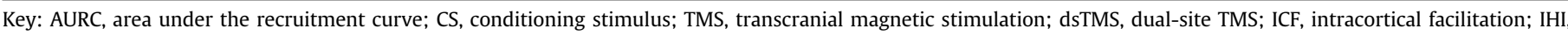

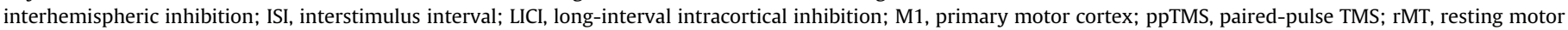
threshold; SICI, short-interval intracortical inhibition; spTMS, single-pulse TMS; TS, test stimulus.

the left M1 hotspot position in a pseudo-randomized order, resulting in a total of 60 recorded MEPs.

\subsubsection{Long-interval intracortical inhibition}

A ppTMS protocol was used to investigate LICI of the left M1. LICI was measured using a $1-\mathrm{mV}$ CS and TS, and a 100-ms ISI. Fifteen conditioned (CS + TS) and 15 unconditioned pulses (TS alone) were applied in a pseudo-randomized order, and a total of 30 MEPs were recorded.

\subsection{Data analysis}

\subsubsection{Magnetic resonance spectroscopy}

Data were analyzed using the Gannet software toolkit (Edden et al., 2013). Individual frequency domain spectra were frequency- and phase-corrected using spectral registration (Near et al., 2015) and filtered with a 3-Hz exponential line broadening. The area under the edited GABA peak at $3 \mathrm{ppm}$ was estimated. This editing scheme coedits approximately $50 \%$ macromolecules at $3 \mathrm{ppm}$, which are coupled to spins at $1.7 \mathrm{ppm}$, also inverted by editing pulses. Therefore, all GABA values are reported as GABA+ (i.e., GABA + macromolecules). GABA+ and unsuppressed water signals were modeled using a single Gaussian peak with a 5-parameter Gaussian model and a Gaussian-Lorentzian model, respectively, and integrated. Next, the MRS voxels were coregistered to the T1-weighted image and the resulting voxels in T1 image space were segmented to determine the different tissue fractions (gray matter, white matter, and cerebrospinal fluid [CSF]) within the voxels (SPM 12). These segmentations were then used to calculate tissue-corrected GABA+ in both voxels with the assumption that GABA+ levels are negligible in CSF and twice as high in gray as compared to white matter (Harris et al., 2015). Moreover, tissue-specific relaxation and water visibility values were taken into account. Finally, GABA levels were normalized to the average voxel composition of our sample of young and older adults (see Harris et al., 2015; equation 6). This full tissue normalization results in a GABA measure that is not simply a measurement of GABA levels in the voxel but a projection of what that measurement would be if the voxel tissue composition were average for the cohort. In addition, water offset frequency SD and fit errors of the GABA peak were calculated to investigate differences in the quality of the MRS data between young and older adults.

\subsubsection{Transcranial magnetic stimulation}

EMG recordings were used to calculate peak-to-peak MEP amplitudes. Trials with EMG activity higher than $5 \mu \mathrm{V}$ peak-to-peak $50 \mathrm{~ms}$ before the first TMS pulse were excluded from the analysis
(MEP recruitment curve left M1: mean young $=7.5 \%$, older $=4.8 \%$; MEP recruitment curve right $\mathrm{M} 1$ : mean young $=7.7 \%$, older $=5.8 \%$; IHI: mean young $=5.1 \%$, older $=9.8 \%$; SICI-ICF: mean young $=4.7 \%$, older $=2.8 \%$; LICI: mean young $=4.3 \%$, older $=3.3 \%$ ). The area under the recruitment curve (AURC) was calculated for the recruitment curve of the left M1 and the right M1 to obtain 1 output measure of overall corticospinal output of the left and right M1s. Next, all measures of the ppTMS and dsTMS protocols were normalized to the corresponding unconditioned MEP using the following equation: conditioned MEP amplitude (CS + TS)/unconditioned MEP amplitude $\times 100$. Values lower than 100 indicate inhibition, whereas values exceeding 100 indicate facilitation relative to the TS alone. This resulted in the following variables of interest: SICI $1 \mathrm{~ms}$, SICI $3 \mathrm{~ms}$, ICF, LICI, IHI $10 \mathrm{~ms}$, and IHI $40 \mathrm{~ms}$.

\subsection{Statistics}

\subsubsection{Group effects}

IBM SPSS Statistics 24 was used for statistical analysis. To evaluate age-related differences in GABA + and TMS metrics of cortical excitation and inhibition, a Student's $t$-test with age group as independent variable was used. T-tests were conducted for GABA+ in SM1 voxel, GABA+ in OCC voxel, AURC of left M1, AURC of right M1, SICI $1 \mathrm{~ms}$, SICI $3 \mathrm{~ms}$, ICF, IHI $10 \mathrm{~ms}$, and IHI $40 \mathrm{~ms}$ and the MannWhitney $U$ test for LICI. A false discovery rate (FDR) controlling procedure for multiple comparisons was used with a 0.05 significance level. For LICI, the data of 1 young participant were excluded because averaged data for this measurement qualified as an outlier ( $>3$ SD from the mean of the age group). In addition, differences in rMT and voxel composition between young and older adults were evaluated with a $t$-test with age group as independent variable.

\subsubsection{Relationship between MRS and TMS metrics}

Correlations were calculated between TMS and MRS metrics in young and older adults separately and combined using the Pearson product-moment correlation coefficient or Spearman's correlation coefficient depending on the distribution (normality) of the data. TMS variables of interest were the AURC for left M1, the AURC for right M1, SICI $1 \mathrm{~ms}$, SICI 3 ms, ICF, LICI, IHI $10 \mathrm{~ms}$, and IHI $40 \mathrm{~ms}$. MRS variables of interest were GABA+ in SM1 and OCC voxel. A FDR controlling procedure was used for each age group separately with a 0.05 significance level.

\subsubsection{Relationships between TMS metrics}

Correlations among the TMS metrics were investigated in young and older adults separately with the Pearson product-moment correlation coefficient or Spearman's correlation coefficient 
depending on the distribution (normality) of the data. TMS variables of interest were the AURC of the left M1, the AURC of the right M1, SICI $1 \mathrm{~ms}$, SICI 3 ms, ICF, LICI, IHI $10 \mathrm{~ms}$, and IHI $40 \mathrm{~ms}$. An FDR controlling procedure was used for each age group separately with 0.05 significance level.

\section{Results}

\subsection{Group effects}

\subsubsection{Magnetic resonance spectroscopy}

A summary of the results can be found in Table 2 . With respect to the SM1 voxel, MRS data of 7 young and 6 older adults were excluded from the analysis due to the following reasons: technical problems with the scanner (young; $\mathrm{N}=3$ ), incorrect voxel placement (young; $\mathrm{N}=1$ and older; $\mathrm{N}=1$ ), and no clear GABA peak in the edited spectrum (young; $\mathrm{N}=2$ and older; $\mathrm{N}=6$ ). With respect to the OCC voxel, MRS data of 3 young adults were excluded from the analysis due to technical problems at the scanner.

Analysis of the segmentation results showed that the gray matter fractions of the SM1 and OCC voxel were significantly lower for older adults compared to young adults (SM1: mean \pm SD young $=0.352 \pm 0.018$, mean \pm SD older $=0.287 \pm 0.024, t(41)=$ $10.294, p<0.001$; OCC: mean \pm SD young $=0.611 \pm 0.031$, mean \pm SD older $=0.530 \pm 0.041, t(51)=7.994, p<0.001)$, while the CSF fractions were significantly higher (SM1: mean \pm SD young $=0.117$ \pm 0.034 , mean \pm SD older $=0.165 \pm 0.037, t(41)=-4.429$; OCC: mean \pm SD young $=0.092 \pm 0.017$, mean \pm SD older $=0.151 \pm$ $0.045, t(35.827)=-6.413, p<0.001)$. White matter fractions were also significantly higher in older adults compared to young adults in the OCC voxel (mean \pm SD young $=0.297 \pm 0.037$, mean \pm SD older $=0.319 \pm 0.036, t(51)=-2.258, p=0.028)$ but not in the SM1 voxel (mean \pm SD young $=0.530 \pm 0.037$, mean \pm SD older $=0.548$ $\pm 0.033, t(41)=-1.701, p=0.096)$. Group analysis of the tissuecorrected GABA+ levels indicated that young and older adults did not differ in the SM1 $[t(41)=0.466, p=0.644]$ or OCC voxels $[t(47.256)=-0.165, p=0.869]$ (Table 2 ). Overall, these observations suggest that, once individual differences in the bulk tissue composition were taken into account, GABA+ levels in both voxels, as quantified here, were not affected by age in the present study sample. Water offset frequency $\mathrm{SD}$, an indication of motion, was significantly higher in older adults compared to young adults in the $\mathrm{SM} 1$ (mean $\pm \mathrm{SD}$ young $=0.421 \pm 0.290$, mean \pm SD older $=0.604$ $\pm 0.232, t(41)=-2.283, p=0.028$ ) and OCC voxel (mean $\pm \mathrm{SD}$ young $=0.512 \pm 0.311$, mean \pm SD older $=0.702 \pm 0.355$, $t(51)=-2.021, p=0.049)$, whereas fit error of the GABA+ peak did not differ significantly between young and older adults [SM1: mean $\pm \mathrm{SD}$ young $=5.033 \pm 1.523$, mean $\pm \mathrm{SD}$ older $=4.519 \pm 1.453$, $t(41)=1.131, p=0.265$; OCC: mean $\pm S D$ young $=4.333 \pm 1.012$, mean \pm SD older $=4.620 \pm 1.440, t(51)=-0.828, p=0.412$ ]

\subsubsection{Transcranial magnetic stimulation}

Three young adults ( 1 woman) and 5 older adults ( 4 women) were excluded from the TMS analyses because the rMT of the right FDI exceeded $60 \%$ of maximum stimulator output. Of the remaining participants (25 young adults [13 women] and 23 older adults [8 women]), 6 young adults ( 2 women) and 3 older adults ( 1 woman) did not complete the recruitment curve measurements of the right hemisphere because the rMT of the left FDI exceeded $60 \%$ of stimulator output. Four young adults ( 1 woman) and 2 older adults ( 1 woman) did not complete the IHI measurements. The number of remaining participants for each TMS measure is indicated in Table 2. TMS measures of SICI $1 \mathrm{~ms}$, SICI $3 \mathrm{~ms}$, LICI, and ICF were only obtained from left M1, whereas IHI $10 \mathrm{~ms}$ and IHI $40 \mathrm{~ms}$ express interhemispheric projections from left to right M1.

The rMT of the left and right hemispheres did not differ between young and older adults for the remaining participants (left M1: mean $\pm \mathrm{SD}$ young $=43.40 \pm 5.45$, mean $\pm \mathrm{SD}$ older $=42.22 \pm 7.15$, $t(41.079)=0.640, p=0.526$; right M1: mean young $\pm \mathrm{SD}=49.05 \pm$ 6.68 , mean \pm SD older $=48.81 \pm 7.41, t(40)=0.109, p=0.913)$. The AURC of the right M1 was larger for older adults compared to young adults $[t(21.822)=-2.330, p=0.029]$; however, the test did not survive FDR correction. The AURC of the left M1 did not differ between the groups $[t(46)=0.129, p=0.898]$. Taken together, these observations suggested that the resting levels of corticospinal excitability for the left and right M1 were not affected by aging (Fig. 2).

There was a significant effect of age on SICI $1 \mathrm{~ms}$ $[t(25.036)=-4.196, p<0.001]$, SICI $3 \mathrm{~ms}[t(28.120)=-3.731, p=$ $0.001]$ and LICI $\left(U=140.000, \mathrm{n}_{\text {Young }}=23, \mathrm{n}_{\text {Older }}=22, p=0.01\right)$, indicating that the levels of intracortical inhibition at rest were significantly lower in older adults compared to young adults. ICF was higher in older adults in contrast to young adults [t(44) $=-2.125, p=0.039$ ]; however, this did not survive FDR correction. Finally, IHI $10 \mathrm{~ms}[t(40)=1.031, p=0.309]$ and IHI $40 \mathrm{~ms}$ $[t(40)=-1.418, p=0.164]$ did not differ between young and older adults, suggesting that interhemispheric inhibition from the left to the right M1 was not affected by aging in the present sample.

\subsection{Relationship between MRS and TMS metrics}

Correlational analyses were performed in young and older adults separately and combined to investigate the degree of

Table 2

Group differences in TMS and MRS metrics

\begin{tabular}{|c|c|c|c|c|c|c|c|}
\hline TMS/MRS metric & $\mathrm{N}$ young & $\mathrm{N}$ older & Mean \pm SD young & Mean \pm SD older & $p$-value & Critical $p$-value & FDR test \\
\hline $\mathrm{SICI} 1 \mathrm{~ms}$ & 24 & 22 & $31.41 \pm 12.08$ & $66.29 \pm 37.23$ & $<0.001$ & 0.005 & 1 \\
\hline SICI $3 \mathrm{~ms}$ & 24 & 22 & $34.12 \pm 21.04$ & $75.86 \pm 48.45$ & 0.001 & 0.01 & 1 \\
\hline LICI & 23 & 22 & $9.94 \pm 22.66$ & $21.28 \pm 25.37$ & 0.01 & 0.015 & 1 \\
\hline AURC right $\mathrm{M} 1$ & 19 & 20 & $55.79 \pm 22.87$ & $102.11 \pm 85.76$ & 0.029 & 0.02 & 0 \\
\hline ICF & 24 & 22 & $144.56 \pm 48.34$ & $194.04 \pm 102.35$ & 0.039 & 0.025 & 0 \\
\hline IHI $40 \mathrm{~ms}$ & 21 & 21 & $82.65 \pm 33.08$ & $70.48 \pm 37.26$ & 0.164 & 0.03 & 0 \\
\hline IHI $10 \mathrm{~ms}$ & 21 & 21 & $86.47 \pm 28.72$ & $75.26 \pm 26.89$ & 0.309 & 0.035 & 0 \\
\hline GABA + sensorimotor cortex & 22 & 21 & $2.58 \pm 0.39$ & $2.53 \pm 0.30$ & 0.644 & 0.04 & 0 \\
\hline GABA+ occipital cortex & 25 & 28 & $3.05 \pm 0.28$ & $3.06 \pm 0.42$ & 0.869 & 0.045 & 0 \\
\hline AURC left M1 & 25 & 23 & $70.78 \pm 49.76$ & $68.80 \pm 56.52$ & 0.898 & 0.05 & 0 \\
\hline
\end{tabular}

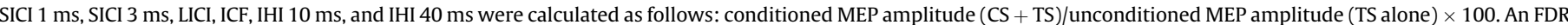

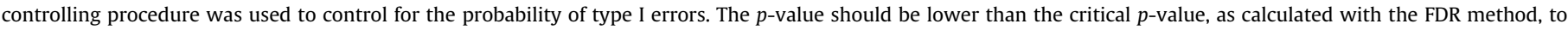
survive multiple comparisons. The column FDR test represents significance after correction for multiple comparisons $(1=$ significant and $0=$ not significant).

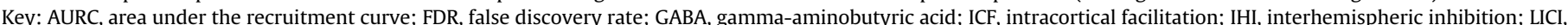

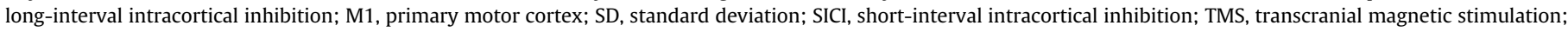
MEP, motor-evoked potentials; MRS, magnetic resonance spectroscopy; CS, conditioning stimulus; TS, test stimulus. 

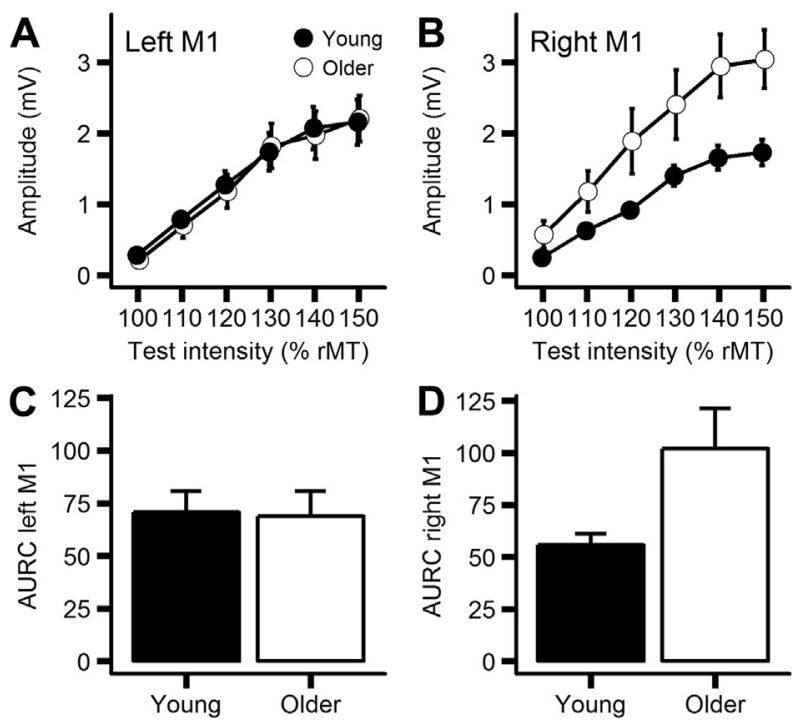

Fig. 2. Group data (mean $\pm S E$ ) for the recruitment curves of the left $(A)$ and right (B) M1. The AURC was compared between young (black bars) and older (white bars) adults. The AURC of the left (C) and the right (D) M1 did not differ between young and older adults after FDR correction. Abbreviations: AURC, area under the recruitment curve; FDR, false discovery rate; M1, primary motor cortex; SE, standard error.

association between TMS variables and tissue-corrected GABA+ levels. A summary of these correlations can be found in Table 3 . We found that IHI $10 \mathrm{~ms}$ was negatively correlated with GABA+ in the OCC voxel in young adults $(r=-0.480, p=0.044)$, however, this did not survive FDR correction (critical $p$-value $=0.00313$ ). All other correlations were not significant (all $p \geq 0.052$ ).

\subsection{Relationships between TMS metrics}

Correlational analyses were performed in young and older adults separately to investigate associations between the TMS metrics (Table 4). With respect to young adults, we found significant negative correlations between IHI $10 \mathrm{~ms}$ and the AURC for the right M1 $(r=-0.638, p=0.003)$, between IHI $40 \mathrm{~ms}$ and the AURC for the left M1 ( $r=-0.630, p=0.002)$, and between IHI $40 \mathrm{~ms}$ and the AURC for the right M1 $(r=-0.681, p=0.001)$. In addition, a significant positive correlation was found between IHI $10 \mathrm{~ms}$ and IHI $40 \mathrm{~ms}(r=0.760, p<0.001)$. With respect to older adults, we found significant positive correlations between SICI $1 \mathrm{~ms}$ and SICI $3 \mathrm{~ms}(r=0.658, p=0.001)$, between AURC for the left M1 and the AURC for the right M1 $(r=0.641, p=0.002)$, and between IHI $10 \mathrm{~ms}$ and IHI $40 \mathrm{~ms}(r=0.616, p=0.003)$. Negative correlations were found between IHI $10 \mathrm{~ms}$ and the AURC for the left M1 $(r=-0.553$, $p=0.009$ ), between IHI $40 \mathrm{~ms}$ and the AURC for the left M1 $(r=-0.533, p=0.013)$, between IHI $40 \mathrm{~ms}$ and the AURC for the right M1 $(r=-0.453, p=0.045)$, and between IHI $10 \mathrm{~ms}$ and SICI $3 \mathrm{~ms}(r=-0.461, p=0.041)$; however, these results did not remain significant after FDR correction (critical $p$-values $=0.007,0.009$, $0.01,0.01$, respectively).

The significance of the difference between the correlation coefficients of young and older adults was tested using the Fisher r-to$z$ transformation. None of the significant correlations were different between young and older adults (all $|z| \leq 1.93, p \geq 0.054$ ).

\section{Discussion}

A first major observation of the present study was that tissuecorrected GABA+ levels in left sensorimotor and occipital regions did not change significantly as a function of age. A second major observation was that tissue-corrected GABA+ levels in the SM1 did not predict GABA-mediated cortical inhibition in either young or older adults, despite significant age-related declines for both SICI and LICI in the older as compared to young adults. Overall, these observations suggest that the decrease in inhibitory functionality of $\mathrm{GABA}_{\mathrm{A}}$ and $\mathrm{GABA} \mathrm{B}_{\mathrm{B}}$ receptors in older adults (as measured with TMS) during rest was unrelated to individual tissue-corrected GABA+ levels in the SM1 (as measured with MRS).

Tissue-corrected GABA levels in SM1 did not differ between the 2 age groups. It is crucial to emphasize that the full tissue correction applied here (Harris et al., 2015) results in a measurement not of the GABA concentration per se but of the GABA concentration that takes into account the tissue characteristics and composition of the voxel studied. This procedure is analogous to measuring singleparticipant hippocampal volumes in standard space, where the resulting metric is not a single-participant volume measurement but an adjusted volume accounting for the brain size. Thus, although the absence of an age effect appears to conflict with some previous MRS studies in healthy older individuals in prefrontal or parietal regions (Gao et al., 2013; Porges et al., 2017), the absence of full tissue correction in these studies means that their results are not fully comparable with ours. In addition, our observations were taken from data collected in 2 extreme age cohorts (young and old), whereas positive evidence for the effect of age on GABA levels reported by Gao et al. (2013) and Porges et al. (2017) were obtained by correlating GABA levels with age in a continuous aging cohort. Finally, some studies reporting reductions in GABA levels as a function of age in prefrontal regions did not report age-related changes in GABA levels across other multiple brain regions such as the thalamus, insula, or cingulate cortex of the healthy aging

Table 3

Correlations between MRS and TMS metrics

\begin{tabular}{|c|c|c|c|c|c|c|c|c|}
\hline MRS metric & AURC left M1 & AURC right M1 & $\mathrm{SICI} 1 \mathrm{~ms}$ & $\mathrm{SICI} 3 \mathrm{~ms}$ & ICF & LICI & IHI $10 \mathrm{~ms}$ & IHI $40 \mathrm{~ms}$ \\
\hline \multicolumn{9}{|l|}{ Young } \\
\hline GABA+ Sensorimotor cortex & $0.101(20)$ & $-0.184(15)$ & 0.439 (19) & $0.159(19)$ & 0.025 (19) & $0.383(18)$ & $-0.094(17)$ & $-0.159(17)$ \\
\hline GABA+ Occipital cortex & $-0.079(22)$ & $0.293(16)$ & $-0.340(21)$ & $-0.227(21)$ & $0.089(21)$ & $-0.266(20)$ & $-0.480(18)^{*}$ & $-0.169(18)$ \\
\hline \multicolumn{9}{|l|}{ Older } \\
\hline GABA+ Sensorimotor cortex & $0.018(17)$ & $0.041(16)$ & $0.121(16)$ & $-0.087(16)$ & $-0.427(16)$ & $0.388(16)$ & $-0.048(17)$ & $-0.030(17)$ \\
\hline GABA+ Occipital cortex & $-0.098(23)$ & $-0.153(20)$ & $0.013(22)$ & $-0.061(22)$ & $0.000(22)$ & $-0.123(22)$ & $0.325(21)$ & $-0.057(21)$ \\
\hline \multicolumn{9}{|l|}{ All } \\
\hline GABA+ Sensorimotor cortex & $0.045(37)$ & $-0.023(31)$ & $0.100(35)$ & $-0.044(35)$ & $-0.238(35)$ & $0.337(34)$ & $-0.038(34)$ & $-0.067(34)$ \\
\hline GABA+ Occipital cortex & $-0.093(45)$ & $-0.097(36)$ & $-0.080(43)$ & $-0.121(43)$ & $-0.004(43)$ & $-0.167(42)$ & 0.089 (39) & $-0.070(39)$ \\
\hline
\end{tabular}

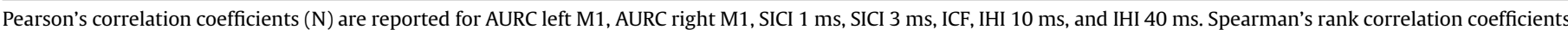
(N) are reported for $\mathrm{LICl}$.

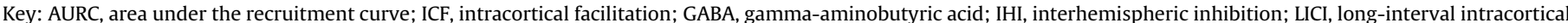
inhibition; M1, primary motor cortex; SICI, short-interval intracortical inhibition; TMS, transcranial magnetic stimulation; MRS, magnetic resonance spectroscopy. ${ }^{*} p<0.05$. 
Table 4

Correlations between TMS metrics

\begin{tabular}{|c|c|c|c|c|c|c|c|}
\hline TMS metric & AURC left M1 & AURC right M1 & $\mathrm{SICI} 1 \mathrm{~ms}$ & $\mathrm{SICI} 3 \mathrm{~ms}$ & ICF & LICI & IHI $10 \mathrm{~ms}$ \\
\hline \multicolumn{8}{|l|}{ Young } \\
\hline AURC right M1 & 0.366 (19) & & & & & & \\
\hline $\mathrm{SICI} 1 \mathrm{~ms}$ & $0.136(24)$ & $-0.238(19)$ & & & & & \\
\hline $\mathrm{SICI} 3 \mathrm{~ms}$ & $-0.031(24)$ & $-0.330(19)$ & $0.177(24)$ & & & & \\
\hline ICF & $0.096(24)$ & $-0.238(19)$ & $0.196(24)$ & $0.170(24)$ & & & \\
\hline LICI & $-0.246(23)$ & $0.245(18)$ & $-0.005(23)$ & $-0.274(23)$ & $-0.087(23)$ & & \\
\hline IHI $10 \mathrm{~ms}$ & $-0.334(21)$ & $-0.638(19)^{* *}$ & $0.123(21)$ & $0.229(21)$ & $0.101(21)$ & $0.027(20)$ & \\
\hline IHI $40 \mathrm{~ms}$ & $-0.630(21)^{* *}$ & $-0.681(19)^{* *}$ & $0.058(21)$ & $0.239(21)$ & $-0.056(21)$ & $-0.111(20)$ & $0.760(21)^{* * *}$ \\
\hline \multicolumn{8}{|l|}{ Older } \\
\hline AURC right M1 & $0.641(20)^{* *}$ & & & & & & \\
\hline $\mathrm{SICI} 1 \mathrm{~ms}$ & $-0.176(22)$ & $-0.359(19)$ & & & & & \\
\hline $\mathrm{SICI} 3 \mathrm{~ms}$ & $-0.039(22)$ & $-0.356(19)$ & $0.658(22)^{* *}$ & & & & \\
\hline ICF & $-0.079(22)$ & $-0.248(19)$ & $0.128(22)$ & $0.247(22)$ & & & \\
\hline LICI & $-0.186(22)$ & $-0.044(19)$ & $0.016(22)$ & $0.129(22)$ & $0.156(22)$ & & \\
\hline IHI $10 \mathrm{~ms}$ & $-0.553(21)^{* *}$ & $-0.230(20)$ & $-0.326(20)$ & $-0.461(20)^{*}$ & $-0.111(20)$ & $-0.020(20)$ & \\
\hline IHI $40 \mathrm{~ms}$ & $-0.533(21)^{*}$ & $-0.453(20)^{*}$ & $0.033(20)$ & $0.210(20)$ & $0.057(20)$ & $0.238(20)$ & $0.616(21)^{* *}$ \\
\hline
\end{tabular}

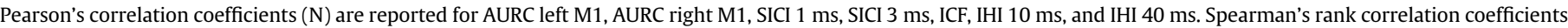
(N) are reported for $\mathrm{LICI}$.

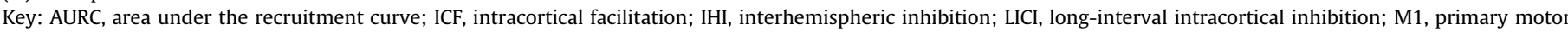
cortex; TMS, transcranial magnetic stimulation; SICI, short-interval intracortical inhibition.

${ }^{*} p<0.05,{ }^{* *} p<0.01,{ }^{* * *} p<0.001$, correlation coefficients in bold survived FDR correction.

brain (Grachev and Apkarian, 2001; Grachev et al., 2001). Taken together, the observations from our study and elsewhere (Grachev et al., 2001) may indicate that the age-related decline in GABA levels is not uniform across the human brain but tends to be more pronounced in anterior than posterior cortical regions. Alternatively, we cannot exclude the possibility that sampling biases may have affected our results.

Notably, regional declines in GABA levels could signify a reduced density of GABAergic inhibitory interneurons that could be triggered by reduction in the complexity of dendrite arborization and length (Dickstein et al., 2007), interneuron loss (Stanley et al., 2012), or alteration in the number of GABA receptors (Gleichmann et al., 2012). These processes are generally consistent with a more rapid decay of gray matter density (Good et al., 2001; Resnick et al., 2003; Ziegler et al., 2012) and decrease in white matter microstructural organization in prefrontal than posterior brain regions (Inano et al., 2011; O'Sullivan et al., 2001; Pfefferbaum et al., 2005; Resnick et al., 2003; Salat et al., 2005; Seidler et al., 2010; Sullivan et al., 2001). Nevertheless, whether age-related alterations in GABA levels are consistent with the anterior to posterior gradient of brain atrophy requires further exploration.

Although older adults did not show reduced GABA levels within the SM1 (after tissue normalization) as compared to young adults, we did observe less inhibition in older adults using TMS. More specifically, older adults showed a significant reduction in the resting-state $\mathrm{SICI}$ and $\mathrm{LICI}$, possibly indicating declines in the activity of $G A B A_{A}$ and $G A B A_{B}$ receptor systems as a function of age. Age-related changes in the activity of $G_{A B A}$ and/or $G A B A_{B}$ receptors have been widely reported in recent literature, and declined performance of voluntary movements in healthy older individuals has been found to be strongly associated with poor regulation of GABAergic activity (Fujiyama et al., 2009, 2012; Heise et al., 2013; Levin et al., 2014; McGregor et al., 2011, 2013; Opie et al., 2015).

Along these lines of evidence, we suggest that individual MRS$\mathrm{GABA}+$ levels are unrelated to the reductions in activation of GABAergic receptor activity within the SM1 as measured in the present study with SICI $1 \mathrm{~ms}$, SICI $3 \mathrm{~ms}$, and LICI $100 \mathrm{~ms}$. Our findings are consistent with most evidence from previous studies in healthy young adults where no significant correlations between GABA levels and TMS measures of SICI 2-4 ms, LICI, or contralateral silent period were observed (Dyke et al., 2017; Stagg et al., 2011b; Tremblay et al., 2013). In contrast, a very recent study investigated the relationship between TMS measures of inhibition and MRS-assessed GABA+ levels in a smaller sample of young and older adults and found a negative correlation between GABA and SICI $1 \mathrm{~ms}$ in young adults (Mooney et al., 2017). However, due to methodological considerations (i.e., small voxel size combined with short acquisition time and the use of gray matter correction), the MRS data quality is likely not reliable and needs to be interpreted with caution (see Mullins et al., 2014 for a more detailed discussion on the impact of these methodological considerations). In addition, it should be noted that the observed reduction in SICI $3 \mathrm{~ms}$ in older adults may be caused by excess facilitation. Previous work has shown that SICI and short ICF interact, particularly at an ISI of $3 \mathrm{~ms}$ (Peurala et al., 2008). Therefore, it is difficult to determine whether the observed age-related reduction in SICI $3 \mathrm{~ms}$ is due to decreased inhibition or increased facilitation. If it is due to excessive facilitation, then the contamination of SICI with short ICF might possibly mask a correlation with GABA+. Taken together, the evidence does not suggest a relation between TMS-obtained measures of inhibition and MRS-obtained GABA+ levels. It should be acknowledged that we had a moderate sample size, and more power might be required to pick up a potential relation between MRS-assessed GABA levels and TMS measures of GABAergic functioning. Therefore, studies with a larger sample size should be carried out to replicate our findings.

GABA can be found in different compartments of the neuron, but it is mostly localized within the cytoplasm and to a lesser extent within synaptic vesicles at presynaptic boutons, where it acts as a transmitter (Martin and Rimvall, 1993). Because the MRS-GABA measurement is thought to mainly reflect GABA levels within the cytoplasm of the GABAergic interneurons (Maddock and Buonocore, 2012; Rae, 2014), it remains unclear whether MRSGABA measures alone could serve as a predictor of age-related changes in GABAergic synaptic activity. Nevertheless, recent evidence indicates that cytoplasmic GABA is related to neurotransmitter release and thus MRS-GABA might still be relevant for the study of GABAergic function, but rather than being a metric of synaptic activity, it is likely to reflect baseline inhibitory tone (Rae, 2014).

The absence of overt correlations between MRS-GABA measures and TMS measures of SICI, LICI, ICF, and IHI in the present study suggests that GABA levels in SM1 do not appear to directly contribute to age-related loss of cortical inhibition, as determined 
by functional measures with TMS observed during rest. Further studies should therefore focus on other contributing factors (such as age-related loss of GABA receptor density or impaired corticocortical interactions due to gray and white matter loss) as underlying mechanisms for suboptimal inhibitory control in healthy aging. For example, studies using animal models reported a reduction in the density of GABAergic interneurons (Hua et al., 2008), age-related loss of the GABA synthetic enzyme glutamic acid decarboxylase (Ling et al., 2005), and an alteration in the composition of $\mathrm{GABA}_{\mathrm{A}}$ receptors (Schmidt et al., 2010; Yu et al., 2006), accompanied by reduced functional inhibition (Schmidt et al., 2010). Alternatively, suboptimal regulation of inhibition might be caused by changes in 1 or more neurotransmitter systems that interact with the GABAergic system. Specifically, it is well known that GABAergic motor interneurons receive strong cholinergic innervation from afferent pathways (Di Lazzaro et al., 2000; Young-bernier et al., 2012) and synaptic input through glutamatergic circuits (Reis et al., 2008). Thus, alterations in these circuits may also impact the functioning of the GABAergic system. Finally, one should consider the possibility that significant associations between MRS-GABA measures and TMS measures of GABAergic inhibition may not be observed in M1 under resting conditions. Indeed, the most striking evidence for the downregulation of the GABAergic system in older adults has been provided by task-related studies (Fujiyama et al., 2012; Heise et al., 2013; Motawar et al., 2016; Opie et al., 2015; Talelli et al., 2008), suggesting that associations between GABA levels and GABAergic synaptic activity could still be present under more dynamic (highdemanding) task conditions.

In contrast to TMS measures of intrahemispheric inhibition (i.e., SICI and LICI), no effect of age was found on corticospinal excitability, ICF, or interhemispheric inhibition from the left M1 to the right $\mathrm{M} 1$. The absence of such an age effect might explain why no correlations with TMS measures of GABAergic synaptic activity were observed. Possibly, the TMS measures of global excitability and interhemispheric inhibition might be more related to glutamate as opposed to GABA levels. Notably, significant correlations between levels of motor corticospinal excitability and MRS glutamate in the SM1 have previously been reported (Dyke et al., 2017; Stagg et al., 2011b). Moreover, interhemispheric inhibition is thought to be mediated by glutamatergic projections from the contralateral hemisphere to the GABAergic motor neuronal system (Chen, 2004; Liuzzi et al., 2010; Perez and Cohen, 2008). As such, glutamate levels within the contralateral hemisphere might possibly serve as a predictor of interhemispheric inhibition.

A final newsworthy aspect of the present study refers to the interrelations between TMS metrics of corticospinal excitability and interhemispheric inhibition. Specifically, we observed significant negative correlations between (1) levels of IHI $10 \mathrm{~ms} / \mathrm{IHI} 40 \mathrm{~ms}$ and the AURC of right M1 and (2) levels of IHI $40 \mathrm{~ms}$ and the AURC of left M1. These negative correlations indicate that higher levels of interhemispheric inhibition from left to right M1 were related to higher levels of excitability of corticospinal neurons. These correlations survived multiple comparison corrections in young but not in older adults. Nonetheless, the pattern is largely convergent and the Fisher r-to-z transformation indicated that the correlations did not significantly differ between young and older adults. The negative correlation between IHI 40 ms and the AURC in left M1 suggests that the activation of inhibitory circuits within the right M1 is partly determined by the level of excitability of the left M1. Because IHI is thought to be mediated by glutamatergic projections from the contralateral hemisphere (Reis et al., 2008), increased glutamatergic signaling within the left M1 might explain both higher levels of excitability of left M1 and the increase in activation of local inhibitory circuits within right M1. Finally, the negative correlations between IHI $10 \mathrm{~ms} / \mathrm{IHI} 40 \mathrm{~ms}$ and the AURC of right hemisphere suggest that the ability to recruit a larger number of corticospinal pathways within the right M1 is related to the ability to activate local inhibitory circuits. This might seem counterintuitive at first sight; however, it might be that glutamate levels in the left and right M1 are similar. Future studies should investigate the potential link between glutamate levels in left and right M1 and TMS measures of interhemispheric interactions.

\section{Conclusion}

Older as compared to young adults demonstrated significantly less resting-state inhibition as measured with the SICI and LICI TMS protocols. This is possibly mediated by changes in $G_{A B A}$ and $\mathrm{GABA}_{\mathrm{B}}$ receptor activity. The observed declines in TMS-assessed inhibition with age were unrelated to MRS-assessed tissue-corrected GABA+ levels within the SM1. Furthermore, we did not find any association between tissue-corrected GABA+ levels within the left SM1 and the degree of motor corticospinal excitability of the left and right M1, ICF within the left M1, or interhemispheric inhibition from the left M1 to the right M1. These findings add to existing literature demonstrating a downregulation of the GABAergic system at rest in older adults. However, because current literature is inconsistent and reports mixed results, it is important to further standardize TMS and MRS protocols to unravel the effect of aging on the GABAergic neurotransmission system and to compare findings across studies. Given that the ability to modulate GABAergic synaptic activity is important for motor performance, further research on the mechanisms underlying the task-related downregulation of this system in older adults is crucial. Notably, the effect of age-related structural brain alterations, such as agerelated decline in $\mathrm{GABA}_{\mathrm{A}}$ receptor density or loss of gray and/or white matter, should be considered.

\section{Disclosure statement}

The authors disclose no conflicts of interest.

\section{Acknowledgements}

This work was supported by the KU Leuven Special Research Fund (grant C16/15/070), the Research Foundation-Flanders (FWO; G089818N), Excellence of Science grant (EOS, 30446199, MEMODYN), and the Francqui Foundation.

\section{References}

Bhandari, A., Radhu, N., Farzan, F., Mulsant, B.H., Rajji, T.K., Daskalakis, Z.J. Blumberger, D.M., 2016. A meta-analysis of the effects of aging on motor cortex neurophysiology assessed by transcranial magnetic stimulation. Clin. Neurophysiol. 127, 2834-2845.

Bhattacharyya, P.K., Phillips, M.D., Stone, L.A., Bermel, R.A., Lowe, M.J., 2013. Sensorimotor cortex gamma-aminobutyric acid concentration correlates with impaired performance in patients with MS. Am. J. Neuroradiol. 34, 1740-1745.

Chen, R., 2004. Interactions between inhibitory and excitatory circuits in the human motor cortex. Exp. Brain Res. 154, 1-10.

Desrosiers, J., Hébert, R., Bravo, G., Dutil, E., 1995. The Purdue Pegboard Test: normative data for people aged 60 and over. Disabil. Rehabil. 17, 217-224.

Di Lazzaro, V., Oliviero, A., Profice, P., Pennisi, M.A., Di Giovanni, S., Zito, G., Tonali, P., Rothwell, J.C., 2000. Muscarinic receptor blockade has differential effects on the excitability of intracortical circuits in the human motor cortex. Exp. Brain Res. 135, 455-461.

Dickstein, D.L., Kabaso, D., Rocher, A.B., Luebke, J.I., Wearne, S.L., Hof, P.R., 2007. Changes in the structural complexity of the aged brain. Aging Cell 6, 275-284.

Dyke, K., Pépés, S.E., Chen, C., Kim, S., Sigurdsson, H.P., Draper, A., Husain, M. Nachev, P., Gowland, P.A., Morris, P.G., Jackson, S.R., 2017. Comparing GABAdependent physiological measures of inhibition with proton magnetic resonance spectroscopy measurement of GABA using ultra-high-field MRI Neuroimage 152, 360-370. 
Edden, R.A.E., Puts, N.A.J., Harris, A.D., Barker, P.B., Evans, C.J., 2013. Gannet: a batchprocessing tool for the quantitative analysis of gamma-aminobutyric acid-edited MR spectroscopy spectra. J. Magn. Reson. Imaging 1452, 1445-1452.

Fujiyama, H., Garry, M.I., Levin, O., Swinnen, S.P., Summers, J.J., 2009. Age-related differences in inhibitory processes during interlimb coordination. Brain Res. $1262,38-47$

Fujiyama, H., Hinder, M.R., Schmidt, M.W., Garry, M.I., Summers, J.J., 2012. Agerelated differences in corticospinal excitability and inhibition during coordination of upper and lower limbs. Neurobiol. Aging 33, 1484.e1-1484.e14.

Gao, F., Edden, R.A.E., Li, M., Puts, N.A.J., Wang, G., Liu, C., Zhao, B., Wang, H., Bai, X., Zhao, C., Wang, X., Barker, P.B., 2013. Edited magnetic resonance spectroscopy detects an age-related decline in brain GABA levels. Neuroimage 78, 75-82.

Gleichmann, M., Zhang, Y., Wood, W.H., Becker, K.G., Mughal, M.R., Pazin, M.J., van Praag, H., Kobilo, T., Zonderman, A.B., Troncoso, J.C., Markesbery, W.R., Mattson, M.P., 2012. Molecular changes in brain aging and Alzheimer's disease are mirrored in experimentally silenced cortical neuron networks. Neurobiol. Aging 33, 205.e1-205.e18.

Good, C.D., Johnsrude, I.S., Ashburner, J., Henson, R.N.A., Friston, K.J., Frackowiak, R.S.J., 2001. A voxel-based morphometric study of ageing in 465 normal adult human brains. Neuroimage 14, 21-36.

Grachev, I.D., Apkarian, A.V., 2001. Aging alters the regional multichemical profile of the human brain: an in vivo $1 \mathrm{H}-\mathrm{MRS}$ study of young versus middle-aged subjects. J. Neurochem. 76, 582-593.

Grachev, I.D., Szeverenyi, N.M., Ramachandran, T.S., Apkarian, A.V., 2001. Aging alters the multichemical networking profile of the human brain: an in vivo $1 \mathrm{H}-$ MRS study of young versus middle-aged subjects. J. Neurochem. 77, 292-303.

Harris, A.D., Puts, N.A.J., Edden, R.A.E., 2015. Tissue correction for GABA-edited MRS: considerations of voxel composition, tissue segmentation, and tissue relaxations. J. Magn. Reson. Imaging 42, 1431-1440.

Heise, K.-F., Zimerman, M., Hoppe, J., Gerloff, C., Wegscheider, K., Hummel, F.C., 2013. The aging motor system as a model for plastic changes of GABA-mediated intracortical inhibition and their behavioral relevance. J. Neurosci. 33, 9039-9049.

Hua, T., Kao, C., Sun, Q., Li, X., Zhou, Y., 2008. Decreased proportion of GABA neurons accompanies age-related degradation of neuronal function in cat striate cortex. Brain Res. Bull. 75, 119-125.

Inano, S., Takao, H., Hayashi, N., Abe, O., Ohtomo, K., 2011. Effects of age and gender on white matter integrity. Am. J. Neuroradiol, 32, 2103-2109.

Irlbacher, K., Brocke, J., Mechow, J.V., Brandt, S.A., 2007. Effects of GABAA and GABAB agonists on interhemispheric inhibition in man. Clin. Neurophysiol. 118, 308-316.

Kim, S., Stephenson, M.C., Morris, P.G., Jackson, S.R., 2014. TDCS-induced alterations in GABA concentration within primary motor cortex predict motor learning and motor memory: a 7T magnetic resonance spectroscopy study. Neuroimage 99, $237-243$.

Kossev, A.R., Schrader, C., Däuper, J., Dengler, R., Rollnik, J.D., 2002. Increased intracortical inhibition in middle-aged humans; a study using paired-pulse transcranial magnetic stimulation. Neurosci. Lett. 333, 83-86.

Kujirai, T., Caramia, M.D., Rothwell, J.C., Day, B.L., Thompson, P.D., Ferbert, A., Wroe, S., Asselman, P., Marsden, C.D., 1993. Corticocortical inhibition in human motor cortex. J. Physiol. 471, 501-519.

Levin, O., Fujiyama, H., Boisgontier, M.P., Swinnen, S.P., Summers, J.J., 2014. Aging and motor inhibition: a converging perspective provided by brain stimulation and imaging approaches. Neurosci. Biobehav. Rev. 43, 100-117.

Ling, L.L., Hughes, L.F., Caspary, D.M., 2005. Age-related loss of the GABA synthetic enzyme glutamic acid decarboxylase in rat primary auditory cortex. Neuroscience $132,1103-1113$.

Liuzzi, G., Horniss, V., Hoppe, J., Heise, K., Zimerman, M., Gerloff, C., Hummel, F.C., 2010. Distinct temporospatial interhemispheric interactions in the human primary and premotor cortex during movement preparation. Cereb. Cortex 20, 1323-1331.

Maddock, R.J., Buonocore, M.H., 2012. MR spectroscopic studies of the brain in psychiatric disorders. Curr. Top. Behav. Neurosci. 11, 199-251.

Martin, D.L., Rimvall, K., 1993. Regulation of $\gamma$-aminobutyric acid synthesis in the brain. J. Neurochem. 60, 395-407.

Mcdonnell, M.N., Orekhov, Y., Ziemann, U., 2006. The role of GABA B receptors in intracortical inhibition in the human motor cortex. Exp. Brain Res. 173, 86-93.

McGinley, M., Hoffman, R.L., Russ, D.W., Thomas, J.S., Clark, B.C., 2010. Older adults exhibit more intracortical inhibition and less intracortical facilitation than young adults. Exp. Gerontol. 45, 671-678.

McGregor, K.M., Nocera, J.R., Sudhyadhom, A., Patten, C., Manini, T.M., Kleim, J.A., Crosson, B., Butler, A.J., 2013. Effects of aerobic fitness on aging-related changes of interhemispheric inhibition and motor performance. Front. Aging Neurosci. 5, $1-14$.

McGregor, K.M., Zlatar, Z., Kleim, E., Sudhyadhom, A., Bauer, A., Phan, S., Seeds, L., Ford, A., Manini, T.M. White, K.D., Kleim, J., Crosson, B., 2011. Physical activity and neural correlates of aging: a combined TMS/fMRI study. Behav. Brain Res. 222, 158-168.

Mescher, M., Merkle, H., Kirsch, J., Garwood, M., Gruetter, R., 1998. Simultaneous in vivo spectral editing and water suppression. NMR Biomed. 11, 266-272.

Mescher, M., Tannus, A., Johnson, M.O., Garwood, M., 1996. Solvent suppression using selective echo dephasing. J. Magn. Reson. Ser. A. 123, 226-229.

Mooney, R.A., Cirillo, J., Byblow, W.D., 2017. GABA and primary motor cortex inhibition in young and older adults: a multimodal reliability study. J. Neurophysiol. $118,425-433$.
Motawar, B., Stinear, J.W., Lauer, A.W., 2016. Delayed grip relaxation and altered modulation of intracortical inhibition with aging. Exp. Brain Res. 234, 985-995.

Mullins, P.G., McGonigle, D.J., O'Gorman, R.L., Puts, N.A.J., Vidyasagar, R., Evans, C.J., Cardiff Symposium on MRS of GABA, Brookes, M.J., Garcia, A., Foerster, B.R. Petrou, M., Price, D., Solanky, B.S., Violante, I.R., Williams, S., Wilson, M., Edden, R.A., 2014. Current practice in the use of MEGA-PRESS spectroscopy for the detection of GABA. Neuroimage 86, 43-52.

Nasreddine, Z.S., Phillips, N.A., Bédirian, V., Charbonneau, S., Whitehead, V., Collin, I. Cummings, J.L., Chertkow, H., 2005. The Montreal Cognitive Assessment, MoCA a brief screening tool for mild cognitive impairment. J. Am. Geriatr. Soc. 53, 695-699.

Near, J., Edden, R., Evans, C.J., Paquin, R., Harris, A., Jezzard, P., 2015. Frequency and phase drift correction of magnetic resonance spectroscopy data by spectral registration in the time domain. Magn. Reson. Med. 73, 44-50.

O'Sullivan, M., Jones, D.K., Summers, P.E., Morris, R.G., Williams, S.C.R., Markus, H.S. 2001. Evidence for cortical "disconnection" as a mechanism of age-related cognitive decline. Neurology 57, 632-638.

Oldfield, R.C., 1971. The assessment and analysis of handedness: the Edinburgh Inventory. Neuropsychologia 9, 97-113.

Opie, G.M., Ridding, M.C., Semmler, J.G., 2015. Brain stimulation age-related differences in pre- and post-synaptic motor cortex inhibition are task dependent. Brain Stimul. 8, 926-936.

Opie, G.M., Semmler, J.G., 2016. Intracortical inhibition assessed with paired-pulse transcranial magnetic stimulation is modulated during shortening and lengthening contractions in young and old adults. Brain Stimul. 9, 258-267.

Opie, G.M., Semmler, J.G., 2014. Age-related differences in short- and long-interval intracortical inhibition in a human hand muscle. Brain Stimul. 7, 665-672.

Peinemann, A., Lehner, C., Conrad, B., Siebner, H.R., 2001. Age-related decrease in paired-pulse intracortical inhibition in the human primary motor cortex. Neurosci. Lett. 313, 33-36.

Perez, M.A., Cohen, L.G., 2008. Mechanisms underlying functional changes in the primary motor cortex ipsilateral to an active hand. J. Neurosci. 28, 5631-5640.

Peurala, S.H., Müller-Dahlhaus, J.F., Arai, N., Ziemann, U., 2008. Interference of shortinterval intracortical inhibition (SICI) and short-interval intracortical facilitation (SICF). Clin. Neurophysiol. 119, 2291-2297.

Pfefferbaum, A., Adalsteinsson, E., Sullivan, E.V., 2005. Frontal circuitry degradation marks healthy adult aging: evidence from diffusion tensor imaging. Neuroimage 26, 891-899.

Porges, E.C., Woods, A.J., Edden, R.A.E., Puts, N.A.J., Harris, A.D., Chen, H. Garcia, A.M., Seider, T.R., Lamb, D.G., Williamson, J.B., Cohen, R.A., 2017. Frontal gamma-aminobutyric acid concentrations are associated with cognitive performance in older adults. Biol. Psychiatry 2, 38-44.

Puts, N.A.J., Edden, R.A.E., 2012. In vivo magnetic resonance spectroscopy of GABA: a methodological review. Prog. Nucl. Magn. Reson. Spectrosc. 60, 29-41.

Puts, N.A.J., Edden, R.A.E., Evans, C.J., Mcglone, F., Mcgonigle, D.J., 2011. Regionally specific human GABA concentration correlates with tactile discrimination thresholds. J. Neurosci. 31, 16556-16560.

Rae, C.D., 2014. A guide to the metabolic pathways and function of metabolites observed in human brain $1 \mathrm{H}$ magnetic resonance spectra. Neurochem. Res. 39, $1-36$.

Reis, J., Swayne, O.B., Vandermeeren, Y., Camus, M., Dimyan, M.A., Harris-love, M. Perez, M.A., Ragert, P., Rothwell, J.C., Cohen, L.G., 2008. Contribution of transcranial magnetic stimulation to the understanding of cortical mechanisms involved in motor control. J. Physiol. 586, 325-351.

Resnick, S.M., Pham, D.L., Kraut, M.A., Zonderman, A.B., Davatzikos, C., 2003. Longitudinal magnetic resonance imaging studies of older adults: a shrinking brain. J. Neurosci. 23, 3295-3301.

Salat, D.H., Tuch, D.S., Greve, D.N., van der Kouwe, A.J.W., Hevelone, N.D. Zaleta, A.K., Rosen, B.R., Fischl, B., Corkin, S., Rosas, H.D., Dale, A.M., 2005. Agerelated alterations in white matter microstructure measured by diffusion tensor imaging. Neurobiol. Aging 26, 1215-1227.

Schmidt, S., Redecker, C., Bruehl, C., Witte, O.W., 2010. Age-related decline of functional inhibition in rat cortex. Neurobiol. Aging 31, 504-511.

Seidler, R.D., Bernard, J.A., Burutolu, T.B., Fling, B.W., Gordon, M.T., Gwin, J.T. Kwak, Y., Lipps, D.B., 2010. Motor control and aging: links to age-related brain structural, functional, and biochemical effects. Neurosci. Biobehav. Rev. 34, $721-733$.

Serbruyns, L., Leunissen, I., Huysmans, T., Cuypers, K., Meesen, R.L., van Ruitenbeek, P., Sijbers, J., Swinnen, S.P., 2015. Subcortical volumetric changes across the adult lifespan: subregional thalamic atrophy accounts for age-related sensorimotor performance declines. Cortex 65, 128-138.

Siebner, H.R., Dressnandt, J., Auer, C., Conrad, B., 1998. Continuous intrathecal baclofen infusions induced a marked increase of the transcranially evoked silent period in a patient with generalized dystonia. Muscle Nerve 21, 1209-1212.

Smith, A.E., Ridding, M.C., Higgins, R.D., Wittert, G.A., Pitcher, J.B., 2009. Age-related changes in short-latency motor cortex inhibition. Exp. Brain Res. 198, 489-500.

Solesio-Jofre, E., Serbruyns, L., Woolley, D.G., Mantini, D., Beets, I.A.M., Swinnen, S.P. 2014. Aging effects on the resting state motor network and interlimb coordination. Hum. Brain Mapp. 35, 3945-3961.

Stagg, C.J., 2014. Magnetic Resonance Spectroscopy as a tool to study the role of GABA in motor-cortical plasticity. Neuroimage 86, 19-27.

Stagg, C.J., Bachtiar, V., Johansen-Berg, H., 2011a. The Role of GABA in human motor learning. Curr. Biol. 21, 480-484.

Stagg, C.J., Bestmann, S., Constantinescu, A.O., Moreno, L.M., Allman, C., Mekle, R. Woolrich, M., Near, J., Johansen-Berg, H., Rothwell, J.C., 2011b. Relationship 
between physiological measures of excitability and levels of glutamate and GABA in the human motor cortex. J. Physiol. 589, 5845-5855.

Stanley, E.M., Fadel, J.R., Mott, D.D., 2012. Interneuron loss reduces dendritic inhibition and GABA release in hippocampus of aged rats. Neurobiol. Aging 33, 431.e1-431.e13.

Stevens-Lapsley, J.E., Thomas, A.C., Hedgecock, J.B., Kluger, B.M., 2013. Corticospinal and intracortical excitability of the quadriceps in active older and younger healthy adults. Arch. Gerontol. Geriatr. 56, 279-284.

Sullivan, E.V., Adalsteinsson, E., Hedehus, M., Ju, C., Moseley, M., Lim, K.O., Pfefferbaum, A., 2001. Equivalent disruption of regional white matter microstructure in ageing healthy men and women. Neuroreport 12, 99-104.

Talelli, P., Waddingham, W., Ewas, A., Rothwell, J.C., Ward, N.S., 2008. The effect of age on task-related modulation of interhemispheric balance. Exp. Brain Res. 186, 59-66.

Temesi, J., Gruet, M., Rupp, T., Verges, S., Millet, G.Y., 2014. Resting and active motor thresholds versus stimulus - response curves to determine transcranial magnetic stimulation intensity in quadriceps femoris. J. Neuroeng. Rehabil. 11, $1-13$.

Tremblay, S., Beaulé, V., Proulx, S., de Beaumont, L., Marjanska, M., Doyon, J., Pascual-Leone, A., Lassonde, M., Théoret, H., 2013. Relationship between transcranial magnetic stimulation measures of intracortical inhibition and spectroscopy measures of GABA and glutamate + glutamine. J. Neurophysiol. 109, 1343-1349.

Wassermann, E., 2002. Variation in the response to transcranial magnetic brain stimulation in the general population. Clin. Neurophysiol. 113, 1165-1171.

Werhahn, K.J., Kunesch, E., Noachtar, S., Benecke, R., Classen, J., 1999. Differential effects on motorcortical inhibition induced by blockade of GABA uptake in humans. J. Physiol. 517, 591-597.

Young-bernier, M., Davidson, P.S.R., Tremblay, F., 2012. Paired-pulse afferent modulation of TMS responses reveals a selective decrease in short latency afferent inhibition with age. Neurobiol. Aging 33, 835.e1-835.e11.

Yousry, T.A., Schmid, U.D., Alkadhi, H., Schmidt, D., Peraud, A., Buettner, A. Winkler, P., 1997. Localization of the motor hand area to a knob on the precentral gyrus A new landmark. Brain 120 (Pt 1), 141-157.

Yu, Z., Wang, W., Fritschy, J., Witte, O.W., Redecker, C., 2006. Changes in neocortical and hippocampal GABA A receptor subunit distribution during brain maturation and aging. Brain Res. 1099, 73-81.

Ziegler, G., Dahnke, R., Jäncke, L., Yotter, R.A., May, A., Gaser, C., 2012. Brain structural trajectories over the adult lifespan. Hum. Brain Mapp. 33, 2377-2389.

Ziemann, U., Lönnecker, S., Steinhoff, B., Paulus, W., 1996. The effect of lorazepam on the motor cortical excitability in man. Exp. Brain Res. 109, 127-135. 